\title{
A simple recursion for power sum polynomials
}

\author{
Helmut Länger \\ Helmut Länger studied mathematics at the Vienna University of Technology where he \\ received his Ph.D. in 1976. Since 1984 he holds the position of an associate professor \\ at the Institute of Discrete Mathematics and Geometry of the mentioned university. \\ Algebra is one of his main research interests.
}

There exists some literature on power sum polynomials and their connection to Bernoulli numbers and Bernoulli polynomials (cf., e.g., [1]-[5]). In this note we provide an elementary proof of a simple recursion for power sum polynomials.

In the following $\mathbb{N}\left(\mathbb{N}_{0}\right.$ resp. $\left.\mathbb{R}\right)$ denote the set of all positive integers (non-negative integers resp. real numbers), let $k \in \mathbb{N}, n \in \mathbb{N}_{0}$ and $x \in \mathbb{R}$ and put

$$
P_{k}(n):=\sum_{i=1}^{n} i^{k-1} .
$$

First we show that $P_{k}(n)$ is a polynomial in $n$ of degree $k$.

Lemma 1.

$$
P_{k}(n)=\frac{1}{k}\left((n+1)^{k}-1-\sum_{i=1}^{k-1}\left(\begin{array}{c}
k \\
i-1
\end{array}\right) P_{i}(n)\right) .
$$

Die Potenzsummen $1^{k}+2^{k}+\cdots+n^{k}$ sind Polynome vom Grad $k+1$ in $n$. Diese Potenzsummenpolynome sind ein beliebter Gegenstand mathematischer Untersuchungen. Die Wurzeln reichen bis in die griechische Antike. Der Ulmer Rechenmeister Johannes Faulhaber legte 1631 den Grundstein zur heute nach ihm benannten Formel für Potenzsummen. Unter anderem befassten sich Jakob Bernoulli und wenig später Leonard Euler mit diesen Polynomen. Deren Koeffizienten stehen in engem Zusammenhang mit den Bernoulli-Zahlen, die wiederum an den unterschiedlichsten Stellen der Mathematik auftreten, so etwa bei der Taylor-Entwicklung des Tangens und des Cotangens oder bei der Berechnung von Werten der Zetafunktion. Der Autor der vorliegenden Arbeit gibt einen neuen Beweis der Rekursionsformel von Dietmar Treiber, der ohne Bernoulli-Zahlen auskommt, und übersetzt die Formel in einen schlanken Algorithmus zur Berechnung der Polynome. 
Proof.

$$
\begin{aligned}
(n+1)^{k}-1 & =\sum_{j=1}^{n}\left((j+1)^{k}-j^{k}\right)=\sum_{j=1}^{n} \sum_{i=0}^{k-1}\left(\begin{array}{l}
k \\
i
\end{array}\right) j^{i}=\sum_{i=1}^{k}\left(\begin{array}{c}
k \\
i-1
\end{array}\right) \sum_{j=1}^{n} j^{i-1} \\
& =\sum_{i=1}^{k}\left(\begin{array}{c}
k \\
i-1
\end{array}\right) P_{i}(n) .
\end{aligned}
$$

Using induction on $k$ we get

Lemma 2. $P_{k}(n)$ is a polynomial in $n$ of degree $k$ with leading coefficient $1 / k$.

Let

$$
P_{k}(n)=\sum_{i=0}^{k} a_{k i} n^{i} .
$$

The following lemma contains some easy properties of the coefficients of $P_{k}(n)$.

Lemma 3.

$$
a_{k 0}=0 \text { and } \sum_{i=1}^{k} a_{k i}=1 .
$$

Proof. $P_{k}(0)=0$ and $P_{k}(1)=1$

Now we can prove a simple recursion formula for the polynomials $P_{k}(x)$.

\section{Theorem 4.}

$$
P_{1}(x)=x \text { and } P_{k+1}(x)=k \int_{0}^{x} P_{k}(t) d t+\left(1-k \int_{0}^{1} P_{k}(t) d t\right) x .
$$

Proof. Since

$$
P_{k+1}(n+1)-P_{k+1}(n)=(n+1)^{k}
$$

for every $n \in \mathbb{N}_{0}$ we have

$$
P_{k+1}(x+1)-P_{k+1}(x)=(x+1)^{k}
$$

for every $x \in \mathbb{R}$. Hence

$$
P_{k+1}^{\prime}(x+1)-P_{k+1}^{\prime}(x)=k(x+1)^{k-1}=k\left(P_{k}(x+1)-P_{k}(x)\right)
$$

and therefore

$$
P_{k+1}^{\prime}(x+1)-k P_{k}(x+1)=P_{k+1}^{\prime}(x)-k P_{k}(x) .
$$

Hence

$$
P_{k+1}^{\prime}(n)-k P_{k}(n)=P_{k+1}^{\prime}(0)-k P_{k}(0)=: a
$$

for all $n \in \mathbb{N}_{0}$ whence

$$
P_{k+1}^{\prime}(x)-k P_{k}(x)=a
$$

for all $x \in \mathbb{R}$. Therefore

$$
P_{k+1}(x)=k \int_{0}^{x} P_{k}(t) d t+a x+b
$$


with some $b \in \mathbb{R}$. Since $P_{k+1}(0)=0$ and $P_{k+1}(1)=1$ we have

$$
b=0 \text { and } a=1-k \int_{0}^{1} P_{k}(t) d t .
$$

Theorem 4 leads to the following algorithm for calculating the polynomials $P_{k}(n)$ :

Algorithm. We have $P_{1}(n)=n$. For $k \in \mathbb{N}$ the polynomial $P_{k+1}(n)$ can be obtained from $P_{k}(n)$ by the following three steps:

(i) Integrate $P_{k}(n)$ with respect to $n$ (with integration constant 0 ).

(ii) Multiply this polynomial by a constant such that the leading coefficient equals $1 /(k+1)$.

(iii) Add a multiple of $n$ such that the sum of the coefficients equals 1 .

We finally demonstrate the usefulness of this algorithm by calculating $P_{k}(n)$ for $k=$ 1, 2, 3, 4, 5:

$$
\begin{aligned}
& P_{1}(n)=n \\
& P_{2}(n)=\frac{n^{2}}{2} \cdot 1+\frac{n}{2}=\frac{n^{2}}{2}+\frac{n}{2} \\
& P_{3}(n)=\left(\frac{n^{3}}{6}+\frac{n^{2}}{4}\right) \cdot 2+\frac{n}{6}=\frac{n^{3}}{3}+\frac{n^{2}}{2}+\frac{n}{6} \\
& P_{4}(n)=\left(\frac{n^{4}}{12}+\frac{n^{3}}{6}+\frac{n^{2}}{12}\right) \cdot 3+0 \cdot n=\frac{n^{4}}{4}+\frac{n^{3}}{2}+\frac{n^{2}}{4} \\
& P_{5}(n)=\left(\frac{n^{5}}{20}+\frac{n^{4}}{8}+\frac{n^{3}}{12}\right) \cdot 4-\frac{n}{30}=\frac{n^{5}}{5}+\frac{n^{4}}{2}+\frac{n^{3}}{3}-\frac{n}{30} .
\end{aligned}
$$

\section{References}

[1] B.C. Berndt, Ramanujan's notebooks, Part I. Springer, New York 1985, 157-158.

[2] K. Dilcher, Zeros of Bernoulli, generalized Bernoulli and Euler polynomials. Mem. AMS 73 (1988).

[3] J. Feldvoss, Über Potenzsummenpolynome. Mitt. Math. Ges. Hamburg 20 (2001), 115-124.

[4] H. Rademacher, Topics in analytic number theory. Springer, New York 1973.

[5] D. Treiber, Zur Kurvendiskussion der Potenzsummenpolynome. Elem. Math. 53 (1998), 119-125.

\section{Helmut Länger}

Vienna University of Technology

Faculty of Mathematics and Geoinformation

Institute of Discrete Mathematics and Geometry

Wiedner Hauptstraße 8-10

A-1040 Vienna, Austria

e-mail: h. laenger@tuwien.ac.at 